Edith Cowan University

Research Online

ECU Publications 2013

$1-1-2013$

Removal of turbidity from water by dissolved air flotation and conventional sedimentation systems using poly aluminum chloride as coagulant

Mehdi Khiadani

Edith Cowan University

Reza Kolivand

Matin Ahooghalandari

Edith Cowan University

Maral Mohajer

Follow this and additional works at: https://ro.ecu.edu.au/ecuworks2013

Part of the Water Resource Management Commons

10.1080/19443994.2013.826339

This is an Accepted Manuscript of an article published by Taylor \& Francis in Desalination and Water Treatment on 02 Aug 2013: Khiadani, M. , Kolivand, R., Ahooghalandari, M. , \& Mohajer, M. (2013). Removal of turbidity from water by dissolved air flotation and conventional sedimentation systems using poly aluminum chloride as coagulant.

Desalination and Water Treatment, 52(4-6), 985-989. Available online here

This Journal Article is posted at Research Online.

https://ro.ecu.edu.au/ecuworks2013/760 


\title{
Removal of turbidity from water by dissolved air flotation and conventional sedimentation systems using poly aluminum chloride as coagulant
}

\author{
Mehdi Khiadani (Hajian) ${ }^{a^{*}}$, Reza Kolivand ${ }^{b}$, Matin Ahooghalandaric $\&$ Maral Mohajer ${ }^{d}$ \\ ${ }^{a}$ Senior Lecturer, School of Engineering, Edith Cowan University, WA 6027, Australia and Environment Research \\ Center, Isfahan University of Medical Sciences, Isfahan, Iran \\ email: m.khiadani@ecu.edu.au \\ ${ }^{b}$ Environmental Health Officer, Ilam University of Medical Sciences, Ilam, Iran. \\ ${ }^{c}$ PhD Candidate, School of Engineering, Edith Cowan University, WA 6027, Australia \\ ${ }^{d}$ Faculty of Engineering , University of Isfahan , Isfahan , Iran
}

\begin{abstract}
Flotation is a method in which particles in liquid phase are transported to the surface by air bubbles. In this experimental study a comparison has been made between conventional sedimentation and dissolved air flotation systems to remove turbidity from water. Initially optimal operational conditions for each system utilized using water artificially turbid with Kaolin. For each system samples were taken at 20 minute intervals after the system reached its optimal operational conditions. Parameters such as turbidity, alkalinity, temperature, $\mathrm{pH}$ and total suspended solids (TSS) was measured.
\end{abstract}

For 20 NTU, 30-50 NTU and 90-110 NTU, turbidity average removal efficiencies in dissolved air flotation system were respectively $14.7 \%, 11.1 \%$ and $10.9 \%$ larger than the conventional sedimentation system. The effect of coagulant dose indicated that dissolved air flotation system with lower dosage of coagulant have higher removal efficiency. On the other hand, the results showed that due to increased efficiency of dissolved air flotation system, solid concentration of sludge produced in this system was more than the sedimentation system ( $\mathrm{p}<0.01$ ). However, operation of dissolved air flotation system needs accurate control devices and experienced technical staff to operate the system.

Keywords: Water treatment, Dissolved air flotation (DAF), Sedimentation, Turbidity, Poly Aluminum Chloride (PAC)

\section{Introduction}

Surface waters are considered as the most significant water supply sources, especially in large communities [1]. Surface waters in their path dissolve different types of impurities that need to be treated. Treatment chain would be selected based on raw water quality conditions, the level of treatment and the type of consumption [2]. To remove particles and other impurities various technologies such as sedimentation, filtration and flotation could be used [3]. In sedimentation system, particles settle due to 
their weight (gravity force). In contrast, in flotation system particles are transferred to the surface taking the advantage of bouncy force. The main advantage of flotation over sedimentation is that small and light particles could be eliminated faster [4]. Therefore in flotation process no need to have high density floccules. In another word, low intensity floccules are required to enhance flotation. The most considerable methods of flotation include air flotation, vacuum flotation and dissolved air flotation (DAF).

In DAF system, air is dissolved in water or wastewater by pressurized air in a saturator. The saturated liquid is injected at the base of contact zone via a set of air diffuser [5,6]. Upon the injection of saturated flow, air bubbles with sizes between 10 and $100 \mu \mathrm{m}$ are produced. In DAF system of low recharge rate, the whole system may be under pressure. In large units, a proportion of water or output wastewater (5$12 \%$ ) is returned to saturator which in this case becomes half-saturated [7]. Returned flow would mix with main flow at the entrance to the saturator.

Sedimentation is defined as an operational unit in which colloids are separated due to their weight. This process is commonly used to treat drinking water and wastewater. The main prospects of this approach in treatment of water could be categorized to: preliminary sedimentation of surface water before slow sand filter, sedimentation of suspended particles before rapid filtration, sedimentation of floccules in lime-soda softening unit, and sedimentation of suspended particles in manganese-ferro removal unit. It has been demonstrated that DAF as in comparison with settling unit is more effective in separating low density particles, and water containing algae, natural color, or low mineral water turbidity $[5,8]$.

Jafarzadeh et al. [9] used DAF system for pre treatment of Karoon river water in Iran. He demonstrates that flotation system is not adequate to remove turbidity from Karoon water and a pre sedimentation system is needed. In his experiments, lack of control on the injection of coagulant materials was one of the limitations. Shahmansouri et al. [10] used DAF system to separate ionic detergent from surface water in Isfahan Water Treatment Plant and a satisfactory result was obtained. Kordmostafapour et al. [11] studied the removal of arsenic and aluminum from raw water using a DAF system using Poly-AluminumChloride (PAC) as a coagulant. They were able to achieve a removal efficiency of $99 \%$ and $99.1 \%$ for arsenic and aluminum, respectively.

Comparison between DAF and conventional sedimentation system showed that DAF is much more efficient in removing turbidity, especially when the water temperature is low [12]. In these experiments, the flotation time in DAF and sedimentation systems was 5 and 20 minutes, respectively. It has been shown that for flotation and sedimentation systems, there is no difference in the amount of required 
coagulant [12,13]. However, flotation system does not require poly electrolyte as supplementary coagulant. A flotation system requires flocs that are porose with low density which can float easily.

The aim of this study was to investigate the efficiency of DAF system against conventional sedimentation system to remove turbidity.

\section{Materials and Methods}

Schematic view of dissolved air flotation and sedimentation systems used in this study are shown in Figs. 1 and 2, respectively. The DAF system consists of a rapid mixing unit of $20 \mathrm{~cm}(\mathrm{~L}) \times 15 \mathrm{~cm}(\mathrm{~W}) \times 15 \mathrm{~cm}$ (H) with a hydraulic retention time of 1 min, a two stage flocculation unit of $26 \mathrm{~cm}(\mathrm{~L}) \times 35 \mathrm{~cm}(\mathrm{~W}) \times 62$ $\mathrm{cm}(\mathrm{H})$ with a hydraulic retention time of $11 \mathrm{~min}$, flotation unit of $96 \mathrm{~cm}(\mathrm{~L}) \times 35 \mathrm{~cm}(\mathrm{~W}) \times 62 \mathrm{~cm}(\mathrm{H})$ with a hydraulic retention time of 12-17 min (depending on the return flow), and saturation units of cylinder shape of $170 \mathrm{~cm}(\mathrm{H})$ and $30 \mathrm{~cm}$ diameter.

In the rapid mixing part of DAF system, water and poly aluminum chloride (PAC) as coagulant was mixed and entered to slow mixing section to allow formation of flocs. Table 1 shows the characteristics of PAC was used in this study. Upon formation of flocs water was entered to flotation region of the system and mixed with saturated water containing small size air bubbles (water was saturated using an air compressor). The flocs were attached to the air bubbles and brought to surface due to buoyancy forces. The system was operated in continues mode having a discharge rate of $0.6 \mathrm{~m}^{3} / \mathrm{h}$. Four different pressures 3, 4, 5 and 6 atmospheres with three different recycle flows (recycle rate) 10\%, 20\% and 30\% were tested.

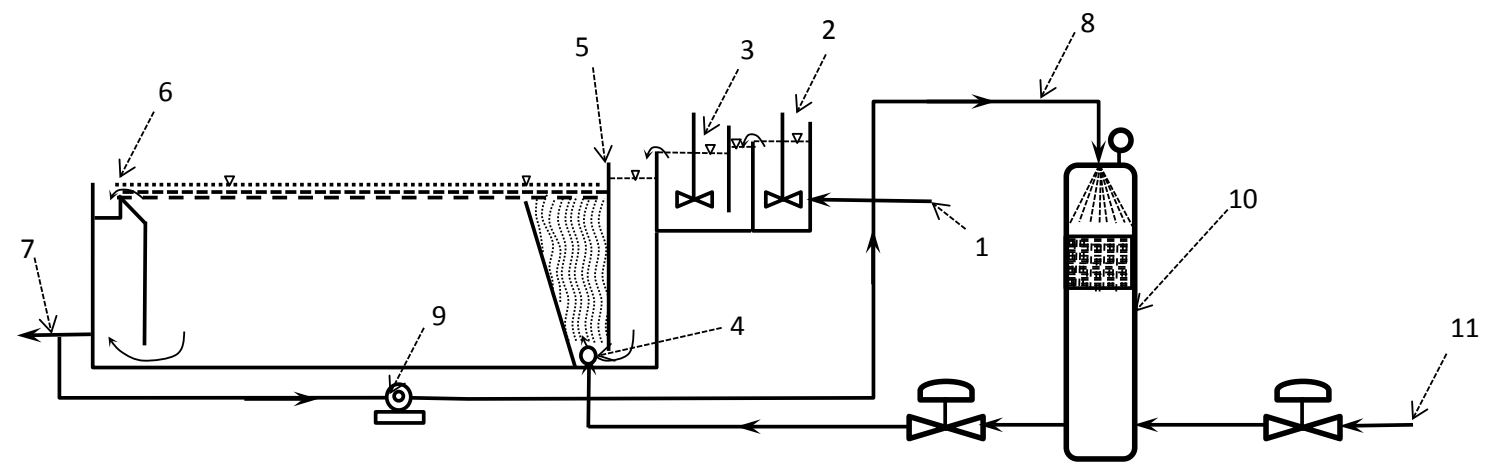

Fig 1. DAF system used in this study: 1- Feed water; 2-Rapid mixing; 3-Flocculants; 4-Air sparger; 5Underflow baffles; 6-Outlet weir; 7-Clean water; 8-Recycled water; 9-Recycled pump; 10-Saturator and 11-Compressed air 
As indicated in Fig. 2, the sedimentation system consists of flocculation and sedimentation units. The flocculation unit was shared between DAF and sedimentation systems. The discharge rate for the sedimentation system was $0.1 \mathrm{~m}^{3} / \mathrm{h}$.

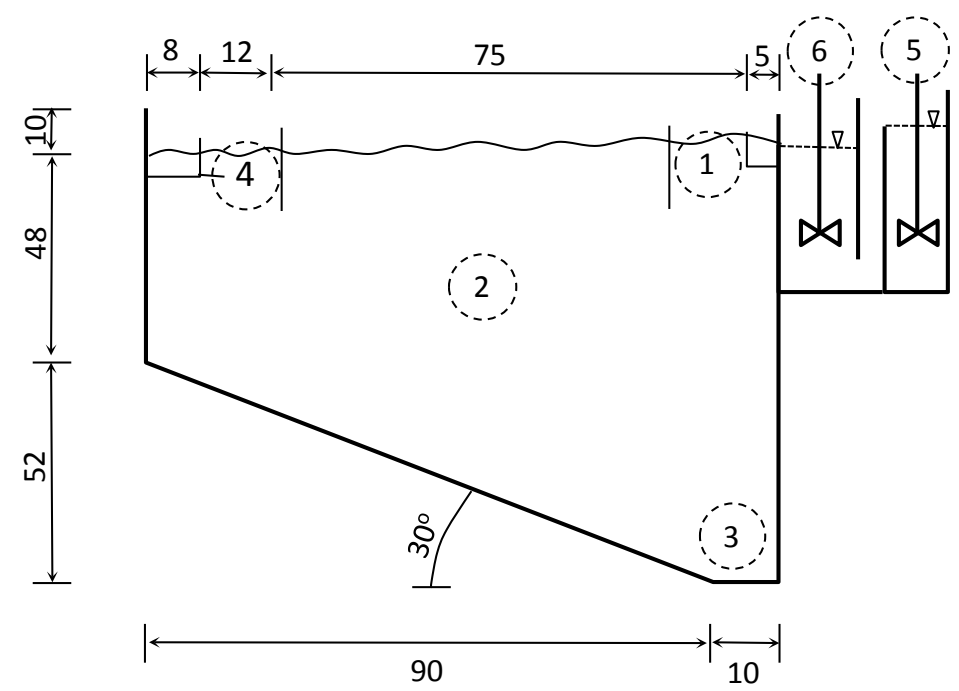

Fig2. Sedimentation system used in this study: 1- Entrance region; 2- Sludge region; 3- Sedimentation region; 4- Exit region; 5- Rapid mixing; 5- Slow mixing (Flocculant). (All units in centimeter)

Table 1. Characteristics of poly aluminum chloride (PAC)

\begin{tabular}{lcc}
\hline \multicolumn{1}{c}{ Parameter } & Unit & Value \\
\hline Appearance & & yellow powder \\
Content of Al2O3 & \% by Mass & $17.5 \pm 1.0$ \\
Basicity & \% by Mass & $45.0 \pm 5.0$ \\
Chloride content & \% by Mass & $20.5 \pm 1.5$ \\
Specific Gravity at $25^{\circ} \mathrm{C}$ & & $1.37 \pm 0.02$ \\
pH of 5\% Solution & w/v & $1.8-4.5$ \\
\hline
\end{tabular}

As part of this study, optimum operational conditions for DAF and sedimentation systems were obtained. The water used in this study was sourced from a bore located in the main campus of the University of Isfahan. Water was stored in a $2 \mathrm{~m}^{3}$ tank and supplied to both systems after its turbidity was artificially adjusted. Parameters such as turbidity, alkalinity, temperature, PH and TSS (Total Suspended Solid) were measured according to standard methods for water and wastewater experiments [14]. Table 2 shows the quality of raw water used in this study. 
Table 2. pH, alkalinity and turbidity of raw water used in this study.

\begin{tabular}{|c|c|c|c|}
\hline Parameter & Minimum & Maximum & Average \\
\hline $\mathrm{pH}$ & 7.3 & 8.3 & 7.9 \\
\hline Alkalinity (mg/l $\left.\mathrm{CaCO}_{3}\right)$ & 130 & 180 & 150 \\
\hline Turbidity (NTU) & 0 & 0.2 & 0.1 \\
\hline
\end{tabular}

Turbidity level in both systems was artificially adjusted using Kaolin $\left(\mathrm{H}_{2} \mathrm{Al}_{2} \mathrm{Si}_{2} \mathrm{O}_{8}-\mathrm{H}_{2} \mathrm{O}\right)$ which was purchased from Merck Company. For each level of turbidity, a certain mass of Kaolin was mixed in one liter backer and its turbidity was measured, then the mass of Kaolin for $2 \mathrm{~m}^{2}$ of water was estimated and added to the supply tank. Three ranges of turbidities 20 NTU, 30-50 NTU and 90-110 NTU were experimented. Poly aluminum chloride doze was varied from $4 \mathrm{mg} / \mathrm{l}$ to $11 \mathrm{mg} / \mathrm{l}$ at $1 \mathrm{mg} / \mathrm{l}$ step using jar test. Table 3 shows condition under which jar tests was conducted.

Table 3. Characteristics of jar test

\begin{tabular}{lcc}
\hline \multicolumn{1}{c}{ Unit } & $\begin{array}{c}\text { Flotation unit } \\
(\mathrm{min})\end{array}$ & $\begin{array}{c}\text { Sedimentation } \\
(\mathrm{min})\end{array}$ \\
\hline Time for rapid mixing (380 rpm) & 1 & 1 \\
Time for slow mixing (30 rpm) & 11 & 35 \\
Time for sedimentation & 30 & 30 \\
\hline
\end{tabular}

The sedimentation and DAF systems were operated under an equilibrium conditions and samples were collected at 20 minutes intervals at the influent and effluent sections of both systems. The samples were analyzed in the water laboratory of Isfahan University of Medical Science.

\section{Results and Discussion}

In order to access turbidity removal in DAF system, different saturation pressures and coagulant concentration have been studied. Fig. 3 shows the removal efficiency of DAF system for turbidity of 25 NTU for 10\%, 20\% and 30\% recycled flow. In these experiments, concentration of PAC was fixed at 4 $\mathrm{mg} / \mathrm{l}$, but pressure was increased from $3 \mathrm{~atm}$ to $6 \mathrm{~atm}$ at $1 \mathrm{~atm}$ step. The results on this figure show that for $\mathrm{P} \geq 4 \mathrm{~atm}$ and recycle water $20 \%$, maximum removal efficiency has occurred. Removal efficiency has not significantly changed when the pressure changes from $5 \mathrm{~atm}$ to $6 \mathrm{~atm}$. It was noticed that when the recycle flow increases to $30 \%$, due to instability in the flow, the removal efficiency slightly reduces. 
Based on these results, it was decided to operate the DAF system for 5 atm pressure and $20 \%$ recycle flow.

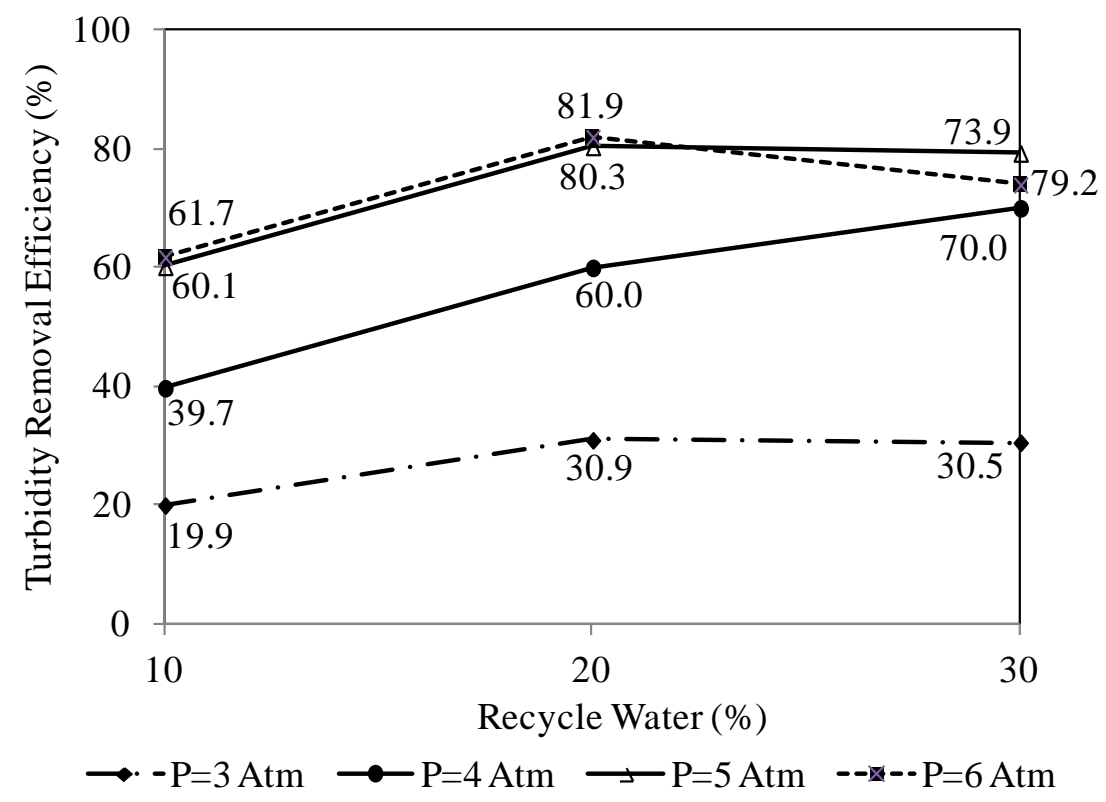

Fig3. Removal efficiency of DAF system

Furthermore, removal efficiency of both systems for various PAC concentrations was assessed and the results are presented in Fig. 4. Results show that, in overall, removal efficiency of DAF system is higher than the sedimentation system. For 20 NTU, 30-50 NTU and 90-110 NTU, average removal efficiencies in dissolved air flotation system were respectively $14.7 \%, 11.1 \%$ and $10.9 \%$ larger than the conventional sedimentation system. Comparison of results from DAF and sedimentation systems shows that at low concentration of coagulant (PAC), the removal efficiency in DAF system is higher. However, as coagulant concentration exceeds $7 \mathrm{mg} / \mathrm{l}$, for turbidity greater than $30 \mathrm{NTU}$, removal efficiency in DAF system decreases. It is likely that zeta potential of kaolin used in this study become less negative as PolyAluminum-Chloride concentration increased. This might have been because the coagulation mechanism changed from one of charge neutralization to sweep coagulation [15]. It is interesting to note that for turbidity 30-50 NTU, removal efficiency in DAF system has not significantly influenced by concentration of coagulant. The results in this study provide information on the fact that DAF has higher efficiency with almost half dosage of PAC required in the conventional (sedimentation) system. 

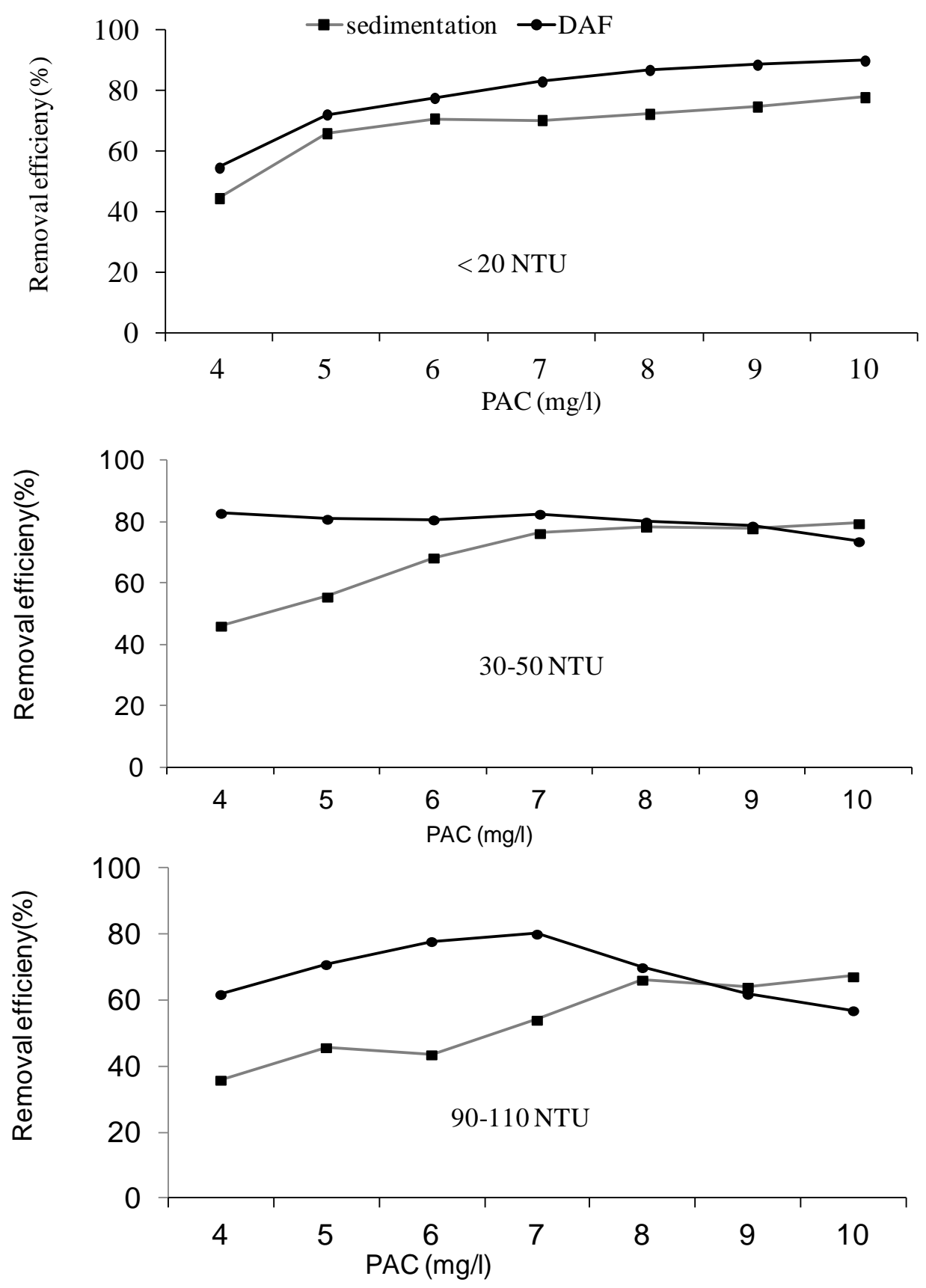

Fig 4. Variation of removal efficiency with concentration of Poly-Aluminum-Chloride in both DAF and sedimentation systems

One of the advantages of DAF system over conventional sedimentation system is the amount of solid sludge that is removed in this system. Fig. 5 compares the percentage of the solid sludge is removed by these systems. As can be seen from this figure, for all level of turbidity was tested, solid sludge produced in DAF system is larger by about 30\%. 


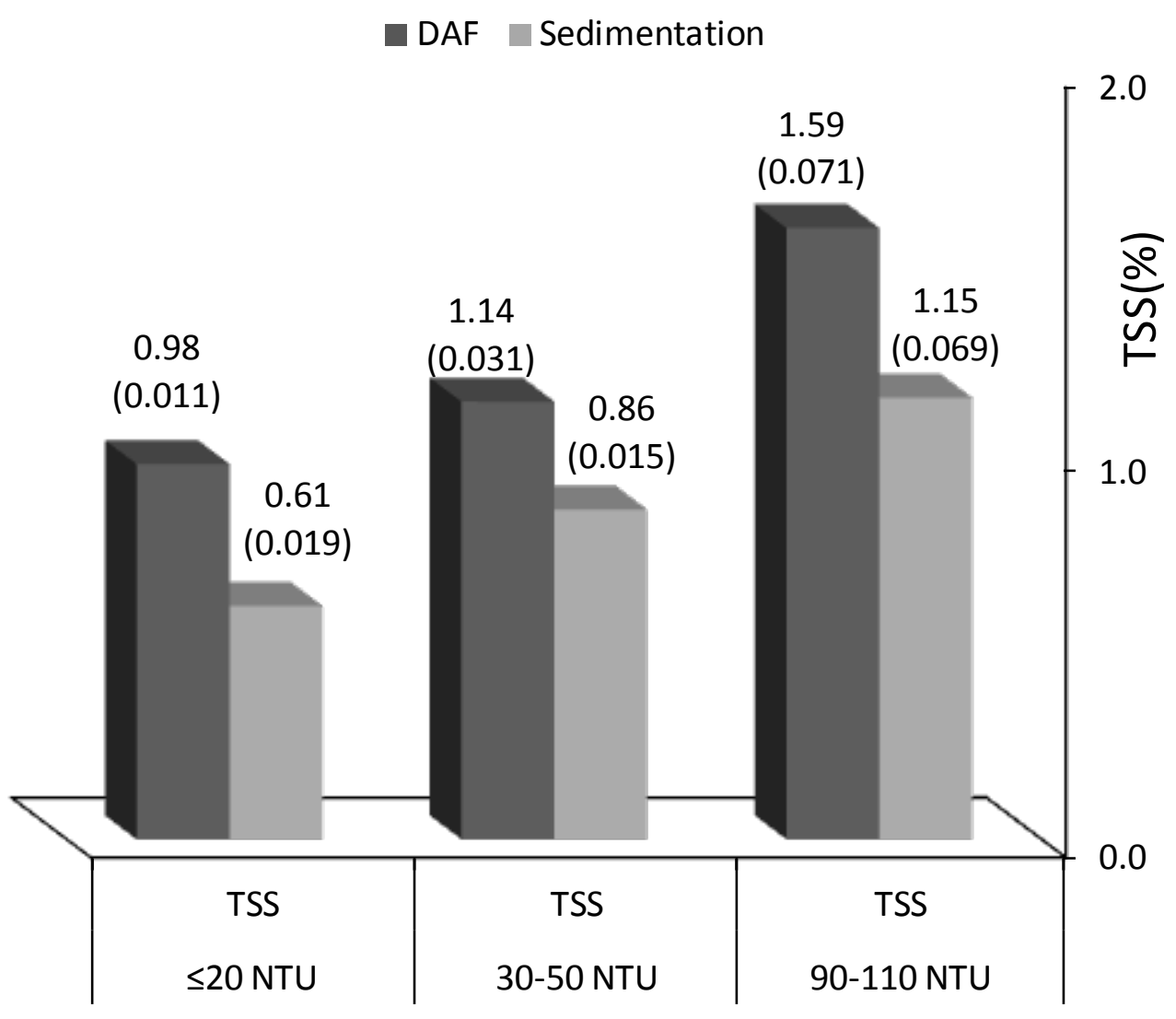

Fig 5. Comparison of average solid sludge in DAF and sedimentation system (numbers in the bracket are standard deviation which is based on three runs, $\mathrm{p}<0.01$ ).

\section{Conclusion}

In this study, DAF and conventional sedimentation systems were compared. The results indicated that DAF system has higher removal efficiency and needs less coagulant as in comparison with conventional sedimentation systems. However, accurate control devices and operational technique is needed to operate the system.

\section{Reference}

[1] S.R. Qasim, E.M. Motley and G. Zhu, Water Works Engineering: Planning, Design, and Operation. Prentice Hall, 2000.

[2] HJ. Kiuru, Development of Dissolved Air Flotation Technology from the First Generation to the Newest (Third) One (Daf in Turbulent Flow Conditions). Water science and technology: a journal of the International Association on Water Pollution Research., 43 (2001) 1. 
[3] J.W. Patterson, Industrial Wastewater Treatment Technology, 1985.

[4] J. Rubio, ML. Souza and RW. Smith. Overview of Flotation as a Wastewater Treatment Technique. Minerals Engineering., 15 (2002) 139-55.

[5] J.K. Edzwald, Dissolved Air Flotation and Me. Water research., 44 (2010) 2077-106.

[6] T. Schofield, Dissolved Air Flotation in Drinking Water Production. Water science and technology: a journal of the International Association on Water Pollution Research., 43 (2001) 9.

[7] J. Farmerie, Dissolved air flotation as a cost effective alternative for potable water clarification. F. B. Leopold Company., (2004) 2-6.

[8] S.P. Liu, Q.S. Wang, W.J. He, H.D. Han, X.H. Fan and T.J. Geng, Comparison of Dissolved Air Flotation and Sedimentation in Treatment of Typical North China Source Water. Process Engineering., 7 (2007).

[9] N. Banisaeid, N. Jafarzadeh, F. Tarkian and G. Eidan, Evaluation of Dissolved Air Flotation (Daf) for Pretreatment of the Karoon River Water. Water and Waste water., (2007).

[10] MH. Mahmoudian, MR. Shahmansoori, MM. Amin and M. Ghasemian, Treatment Spent Filter Backwash Water Using Dissolved Air Flotation (Daf) in Isfahan Wtp. Water Practice \& Technology., 3 (2008).

[11] F. Kordmostafapour, H. Pourmoghadas, MR Shahmansouri and A. Parvaresh, Arsenic Removal by Dissolved Air Flotation. Journal of Applied Sciences., 6 (2006) 1153-58.

[12] J.K. Edzwald and J.P. Walsh, Dissolved Air Flotation: Laboratory and Pilot Plant Investigations. AWWA Research Foundation and American Water Works Association, 1992.

[13] W. Fuqi, Z. Yuemei, Z. Yiqing and Y. Jing, Application of Polyaluminum in Dissolved-Air Flotation Process. Water Technology, 4 (2008) 013.

[14] L.S. Clesceri, AD. Eaton, AE. Greenberg and EW. Rice, Standard Methods for the Examination of Water and Wastewater. Centennial Edition, 21st edn). American Public Health Association: Washington, DC, 2005.

[15] M. Han, S. Dockko and C. Park, Calculation of Collision Efficiency Factor by Trajectory Analysis in Dissolved Air Flotation. KSCE Journal of Civil Engineering., 2 (1998) 91-95. 